\title{
The Genesis of Philosophy and the Theological Aspect of Human Self-consciousness
}

\author{
Alexander Glazkov ${ }^{1, *}$ Leonid Podvoisky ${ }^{1, a}$
}

\author{
${ }^{1}$ Department of Philosophy, Astrakhan State University, Astrakhan, Russia \\ aEmail: leonid.podv@gmail.com \\ *Corresponding author. Email: alpglazkov@yandex.ru
}

\begin{abstract}
The subject of research in the article is theology, one of the types of knowledge and one of the disciplines taught in higher education. The purpose of the article is to determine the significance of theology as a scientific methodological approach based on philosophical analysis. Theology is considered as a way of expressing the structural moments of the mode of self-consciousness, and belongs to its sphere of ideals. Through a study of the genesis of philosophy, which is considered in the context of the formation of developed forms of self-awareness, the role of theology as a form of cognitive activity is revealed. Consideration of the sphere of ideals allows us to clarify its functional role in the structure of self-consciousness and determine the relationship of this sphere with theology as a methodological aspect of scientific research. The research methodology includes a logical analysis and a historical approach to identify the specifics of the process of forming the ideal sphere of selfconsciousness. The scientific novelty of research consists in justification of theology as a necessary element for the formation of self-consciousness; in establishing the significance of theology in the formation of the sphere of ideals necessary for self-awareness; in substantiating theological as a methodological approach in scientific knowledge, the use of which allows you to more holistically explore the spiritual world of man.
\end{abstract}

Keywords: philosophical theology, mythopoetic theology, self-awareness, ideals, speculative myth, metaphysics

\section{INTRODUCTION}

Theology is usually associated with cognition that is not related to reality and, therefore, cannot be associated with science. At the same time, theology is a specific and is substantial field of knowledge, and in this status it is an integral part of the culture of mankind. In this regard, the definition of the meaning that theology plays in the spiritual life of a person will reveal its heuristic potential in scientific knowledge and, above all, in the Humanities. Spiritual life is all events and processes that are connected with a person's self-consciousness. Therefore, the definition of the heuristic potential of theology lies, on the one hand, in the field of studying the history of the formation and development of self-consciousness, and on the other hand, in clarifying the ontological foundations of theology, that is, theologicity as a natural quality to human nature, which manifests itself in intellectual acts. We can trace the formation and development of self-awareness in the framework of the study of the genesis of philosophical theology, and consideration of the role and importance of the sphere of the ideals of self-consciousness revealed through the study of the essential mechanism of the formation of theologicity.

The knowledge with which theology deals, and which it forms in a certain way, belongs to the religious sphere of human being. The phenomenon of religiosity is the basis of all its possible variants and aspects. In this case, religiosity is understood as religiosity as such, a characteristic feature of consciousness, which takes as reality the sphere of the invisible "supernatural", "ideal", "perfect", "divine" world, through which the visible world is perceived by sensations is understood. What distinguishes theology into a separate type of understanding relates more to the way of expressing religiosity and characterizes the level of development of self-consciousness that is assimilated by society as a whole. The word "theology" also fixes the modus of understanding and formalization of religious views. In this meaning, theology coincides with philosophy. The problem is to find out how theology transfers religiosity from the sphere of spontaneous subjective knowledge to the level of awareness and rationally grounded objective understanding. 


\section{THE GENESIS OF PHILOSOPHY AND THE FORMATION OF THEOLOGY}

In contrast to ordinary or mythological religiosity, the theological version of it represents a qualitatively different degree of awareness, thoughtfulness and systematization of religious views. Already a mythopoetic, subjective in its origin and content accordingly version of the theology of Homer and Hesiod, preceding the appearance of philosophy, as A.V. Semushkin has convincingly proved, points to the separation of individualizing self-consciousness from consciousness dissolving in collective anonymous myth-making. As writes A. V. Semushkin: "From anonymous and consecrated by tradition myth-making is personalized in the creativity of separate individuals capable of a highly intellectual life" [1]. It is at this moment that it becomes "reflective", "theologizing". The myth becomes "speculative". Thus Homer, who together with Hesiod is considered the codifier of ancient Greek mythology, "in his aesthetic rationalism has already outgrown the boundaries of traditional myth and, therefore, must be considered in the context of the Genesis relationship with the emerging philosophy" [2]. The spiritual transformation "from myth to logos" occurs through a change in the forms of self-awareness. The next step in the formation of self-consciousness within the movement "from myth to logos" leads to the emergence of philosophical theology, which appears in the works of the first philosophers of Ancient Greece, who "do not so much start a new, but rather complete (or rather pick up) the long process of decomposition of traditional mythology, its displacement by personalized forms of worldview development of reality" [3]. Finally, philosophical theology gets its more or less complete formalization in the 6th book of Aristotle's Metaphysics called "the first philosophy".

The question that arises in this connection can be formulated as follows: why do theology and philosophy arise simultaneously, in synthesis, and represent a joint interdependent genesis? The reason lies, suggest, in the features of the internal ontological mechanism of creation of the formation and development of human self-consciousness. The word "theology" fixes the layer of consciousness that is necessary for self-awareness as an opportunity, which includes the sphere of images, which in the spiritual world of a person receive the status of "perfect", that is, ideals that are absolute in meaning. These ideals become criteria for selfevaluation. Through this sphere of ideals of consciousness conditioned by human nature, a mechanism of rationally substantiated critical consideration of oneself arises during the transformation of mythological consciousness. Mythological consciousness also has its own ideal sphere, but "in the myth is fixed the alienated ideal of human life", and "it is a realized ideal, but not realized for a real person", but for "a superman or god". With this ideal, a person does not compare himself, and "does not strive for it" [4]. The ideal in this mythological consciousness is "not the supposed future of man, but eternally present for the gods" [5]. The identification of individuality and, accordingly, the correlation of the sphere of the ideal with itself begins with the advent of a speculative - theoretical myth, and then gets its development in early philosophy. As A.V. Semushkin writes: "Theoretical thinking in a speculative myth is carried out as knowledge of the divine, theology" [6]. The mythological ideal sphere is thus theologized in a speculative myth. Theologization becomes a tendency, defined by a spiritual algorithm, which ultimately transforms speculative myth into new, already philosophical forms containing rational constructions, categories, abstract concepts through which the content of absolute ideals is understood.

The first philosophers have a "different kind of vision" focused on the discovery of the first beginning, which must still be revealed through "intelligent" perception and representation. There is a speculative world, a theoretical sphere through which spiritual rational self-knowledge is possible. As S.A. Nizhnikov notes: "A man finds himself a resident of two worlds, as it were, which are opposed to each other in everyday consciousness. In fact, the sphere of speculation is not the opposite of the sensory, but is its truth. They relate to each other as be and being, as essence and existence. This kind of speculative knowledge is defined as metaphysics " [7]. The theology of speculative myth is transformed from mythopoeic to philosophical, and philosophy in its search for the original becomes theological. From this moment, philosophy and theology constitute a single theoretical science metaphysics, a kind of "theo-philosophy". This is a natural process and it develops further in the history of philosophy, acquiring different directions, outlines and aspects. Breaking the connection with myth, metaphysics instead develops theoretical doctrines, establishes the rules of cognition, which as a result receives a methodology. As a result, the sphere of ideal manifests itself more clearly within consciousness - it is theorized and theologized.

Thus, theology is a certain stage in the expression of religiosity in the formation and development of selfconsciousness. As A.V. Semushkin writes: "From the point of view of the transition from Myth to the Logos of worldview, the philosophical initiative of Thales does not look like a beginning, but a continuation of previous efforts and achievements" [8]. Thales takes a step forward in the development of theoretical thinking. Through this step, theology acquires the special quality of "philosophic", becomes philosophical in its form of expression. At this moment, a combination of theology-specific religiosity as an internal quality of the semantic content of perfection and the philosophyspecific rationality as a way of spiritual cognition of a 
person takes place. Philosophical theology arises - theophilosophy, as a type and direction of intellectual activity, which has its own specifics, the history of formation and development in all its branches. This philosophical theology can be brought closer to the term "metaphysics" and distinguished from all other fundamentally different types of theology.

Philosophical theology is a form of more developed individualizing self-consciousness, which through the use of logic, introducing and spreading the rational principles of self-awareness, tries to overcome the subjectivity of poetic religious understanding. At this level of formation of self-consciousness, reached within the framework of ancient philosophy, the natural philosophical theology begins to develop in depth and breadth, in a variety of directions, detailing the problems and questions that arise in the process of this development, and which appear depending on the mental and cultural characteristics of society. There is a disclosure of internal potential inherent opportunities for spiritual development of a man. The desire for analytical, rationalization, thoughtfulness, methodological and logical rigor of presenting one's positions is a natural tendency in this process. Actually, this aspiration connects theology with philosophy, which by its nature is a rational way of selfconsciousness. This tendency continues to the present time and finds, for example, its embodiment in "philosophical theology", a discipline that arose within the framework of analytical philosophy, "whose material object is quite ancient, but whose methodological approaches and formal object are constantly updated" [9]. In a sense, "philosophical theology" can be distinguished from "natural theology". If "natural theology", as V.K. Shokhin notes, was formed in the framework of Western Christian scholasticism, then philosophical theology "could be designated as intercultural philosophical discourse" [10]. In this interculturality we can just notice its universal and natural essential moment for the formation and development of self-consciousness.

\section{THE SPHERE OF IDEALS AND THE IDEAL NATURE OF CONSCIOUSNESS}

Theology as a form of individualization of consciousness regulates the sphere of the ideal, perfect, divine, true, forms the criteria through which critical self-knowledge is now realized and, accordingly, the judgment about the events and actions of other people. Critical self-knowledge, in turn, "solitary" the individual, distinguishes him from the mass of people. Theology, in conjunction with philosophy, objectifies this process, introduces into it through rational justification the desire to overcome subjectivity in establishing criteria for perfection.
In the centuries-old history of philosophy as a special way of forming a worldview, and as a special science, there are a number of categories that, on the one hand, are of the central importance, and on the other hand, they are still insufficiently developed. One of these cross-cutting categories is the category "consciousness". But consciousness cannot be more or less satisfactorily considered without its close connection with the category of "ideal".

As a separate concept, the category "ideal" appears relatively late, in comparison or in relation to the material. The term "ideal" most likely dates back to the Greek concept of "idea" - "prototype". Three important properties can be distinguished in the "ideal" category: a) the ideal image is immaterial and non-stretched; b) the ideal image has a substantial resemblance to the subject conjugated with it; c) an ideal image can become part of the subjective world of man. The ideal serves as a model for reproducing the class of real objects, acts as their essence.

We often use the concept of "idea" as a synonym for the design of something that does not yet exist, but that in the future may manifest itself, materialize, be filled with some specific content and take on a specific form. The concept of an idea is closely related to the concept of an ideal. The ideal, if we follow the thoughts of Socrates and Plato, is a kind of model by which we can judge our own shortcomings, the shortcomings of things, etc., a model to which we must strive. From the concept of Ideal, we logically pass on to the term "ideal," which means for our minds exemplary, perfect, corresponding to the ideal or striving for it; and also ideal, existing only as an idea, not real, not real, ideal being.

Without setting as our task the consideration of the concepts of "idea", "Ideal", "ideal", "consciousness" on purpose and in detail, we confine ourselves to just a few key points for this work. It is safe to say that the concept of the ideal in a more or less definite form arose in the philosophy of Plato, finding its expression in the concept of "idea". According to Plato, an idea exists separately from a thing, being its essence. The idea is objective, which is reflected in his system of objective idealism, which is a double world - the world of ideas and the world of things.

We can talk about two worlds in the context of the existence of two realities. As D. Kehoe notes: "We live simultaneously in two worlds, two realities: the internal reality of our thoughts, feelings and views and the external reality, where people, places and events exist" [11]. The inner reality is ideal in its nature and in it we distinguish the sphere of ideals. The ideal sphere, as a necessary element of self-consciousness, is expressed in words. As known, each concept is denoted by a word or phrase. In this regard, it is appropriate to cite the thought of the psychologist A.R. Luria. He states that 
the history of the language "is the history of the emancipation of a word from practice, the separation of speech as an independent activity that fills the language and its elements - words - as an independent system of codes, in other words - the history of the formation of the language in such a way when it began to enclose everything the necessary means for designating the subject and expression of thought - (italics AR Luria)" [12]. Through the word the ideal nature of self consciousness is provided and consequently the possibility of self consciousness is realized.

Another important point is the question of the possibility of the objective reality of the ideal, its separation from the subjectivity of consciousness. According to the concept of D.I. Dubrovsky, the ideal is a phenomenon that is inherent in the subjective world of a separate social individual, its material carrier is a neurodynamic code, the nature of which is still not clear to science. As D.I. Dubrovsky notes: "It is more logical to call ideal any knowledge that exists in the form of subjective reality. The category of the ideal covers the whole range of phenomena of subjective reality" [13]. At the same time, as E.V. Ilyenkov notes: "The definition of the ideal, that is, is purely dialectical. This is what is not and at the same time is. This is something that does not exist in the form of an external, sensually perceived thing, and at the same time exists as an active human ability. This is being, which, however, is equal to non-being, or the existing being of an external thing in the phase of its formation in the activity of the subject, in the form of his internal image, need, motivation and goal" [14]. In general, according to the concept of E.V. Ilyenkov ideal is born and exists in human social activity. It turns out that the ideal is a special kind of objective reality. The primary manifestation of the ideal is the scheme of practical activity; practice is a certain class of objects in the sequence and nature of operations, i.e. in the scheme of practical activity with this class of objects. The secondary manifestation of the ideal is a subjective image.

Thus, our inner reality, the reality of our consciousness, being ideal in nature, also includes the sphere of ideals, without which self-consciousness is practically impossible. The sphere of ideals can have different forms of expression, not all ideas about the ideal and perfection are actually such, since there is subjectivism in these ideas, but the essence does not change from this, for the individual - this is the sphere of the perfect, through which it carries out a critical self-assessment of its qualities This position initially corresponds to theologicity as a characteristic of the perfect and supernatural. The concept of "theology" as a characteristic of ability in this case is not directly related to any religion. We are talking about a certain aspect that has methodological significance, and which has its basis in the cognitive ability of consciousness.

\section{CONCLUSION}

Thus, historically, the formation of individual selfconsciousness took place with the participation of theology as a specific ability of consciousness to develop the sphere of ideals. Through the sphere of ideals, self-awareness is possible. This ability can be described by the concept of "theologicity of consciousness". In this process, theology is related to philosophy, which is a rational way of self-awareness The formation of philosophical theology as a special field of knowledge, which in its various versions has been successfully developed to date, and one of its promising areas is the discipline "philosophical theology", which arose within the framework of analytical philosophy.

The definition of the role of theology in the formation of the sphere of ideals of self-consciousness allows us to clarify its methodological significance, to reach an understanding of the heuristic function of theology in scientific knowledge. The study of the functional significance of ideals in the activity of consciousness leads to the conclusion about the need for a theological measurement of the studied phenomena of reality. This is the onto-epistemological basis of theology as theologicity. Objectively, theology is the domain of perfection, ideal as an ideal, beyond the real-material area. This position allows us to talk about the theological dimension of the object of research, which in turn allows us to achieve the integrity of knowledge. It is possible to use the concepts of "theological aspect", "theological dimension", "theologicity" of a phenomenon of reality. Through these methodological guidelines, a complete knowledge can be achieved, in which the ideal theological, rational-philosophical and scientificempirical approaches are organically linked, as the famous Russian philosopher V. S. Solovyov put it at the time: "The circle of knowledge, in which the empirical content prevails and the main interest belongs to material truth, forms the so-called positive science; knowledge, determined mainly by general principles and having in mind primarily logical perfection or formal truth, forms an abstract philosophy; finally, knowledge, which has absolute reality as its first subject and starting point, forms theology" [15]. Thus, the concept of "theology" clarifies the nature of spiritual life and can be used as a scientific aspect, a methodological approach that allows us to reveal the dimension of the ideal, perfect, relating to the phenomena of spiritual, cultural social life.

\section{References}

[1] A.V. Semushkin, "Myth as mother's bosom of philosophy", Selected works in 2-vol. vol.1. Moscow: RUDN, 2009, pp. 465638, p.495 
[2] A.V. Semushkin, "The genesis of ancient Greek philosophy", Selected works in 2-vol. vol.1. Moscow: RUDN, 2009, pp.15264, p.55.

[3] A.V. Semushkin, "The genesis of ancient Greek philosophy", Selected works in 2-vol. vol.1. Moscow: RUDN, 2009. pp.15264. p.55.

[4] A.V. Semushkin, "Myth as mother's bosom of philosophy", Selected works in 2-vol. vol.1. Moscow: RUDN, 2009, pp. 465638, p.503.

[5] A.V. Semushkin, " Myth as mother's bosom of philosophy ", Selected works in 2-vol. vol.1. Moscow: RUDN, 2009, pp. 465638, p.503.

[6] A.V. Semushkin, " Myth as mother's bosom of philosophy ", Selected works in 2-vol. vol.1. Moscow: RUDN, 2009, pp. 465638, p.572.

[7] S.A. Nizhnikov, "Ancient Greek metaphysics: genesis and classics", Moscow: INFRA-M, 2013. p.216 p. 39.

[8] A.V. Semushkin, "The genesis of ancient Greek philosophy", Selected works in 2-vol. vol.1. Moscow: RUDN, 2009, pp.15264, p.58.

[9] Romerales Enrique "Philosophical Theology", Filosofía de religión: estudios y textos. Madrid: Edición de Manuel Fraijó Editorial Trotta, p.558-599, p.559

[10] V.K. Shokhin "Philosophical theology and basic theology", Vestnik PSTSU, Series I: Theology, Philosophy, Religious Studies, 2014, Vol. 1, pp. 57-79, p.62.

[11] J. Kehoe, "Subconscious mind can do anything!", Minsk: "Potpourri", 2009, 176 p., p. 15.

[12] A. R. Luria "Language and consciousness", Rostov n/D: publishing house "Phoenix", 1998, 416 p. p. 34.

[13] D.I. Dubrovsky "The problem of the ideal. Subjective reality", Moscow: Kanon+, 2002, 368p., p.69

[14] E. V. Ilyenkov "Ideal", Philosophical encyclopedia, vol. 2, Moscow: publishing house "Soviet encyclopedia", 1962, pp.219-227, p.222.

[15] V. S. Solovyov, "Philosophical principles of integral knowledge", Works in 2-vol., vol.2., Moscow: Thought, 1988, pp.139-288, p.149. 